\title{
Novel SPAST deletion and reduced DPY30 expression in a Spastic Paraplegia type 4 kindred
}

\author{
Loretta Racis ${ }^{1,2}$, Eugenia Storti ${ }^{3}$, Maura Pugliatti ${ }^{1}$, Virgilio Agnetti ${ }^{1}$, Alessandra Tessa ${ }^{3}$ and Filippo M Santorelli ${ }^{3 *}$
}

\begin{abstract}
Background: The hereditary spastic paraplegias (HSPs) are pleiomorphic disorders of motor pathway and a large number of affected genes have been discovered. Yet, mutations in SPG4/SPAST represent the most frequent molecular etiology in autosomal dominant (AD) patients and sporadic cases. We describe a large, AD-HSP Sardinian family where 5 out of several living members harbored a novel deletion affecting also the 5'UTR of SPAST and resulting in reduced expression of DPY30, the gene located upstream SPAST in a head-to-head manner.
\end{abstract}

Case presentation: A 54-year-old woman manifested leg stiffness at age 39 and required a cane to walk at age 50. Neurological examination disclosed mild spasticity and weakness in the legs, hyperreflexia in all limbs, and bilateral Babinski sign. She also complained of urinary urgency, but no additional neurological symptoms or signs were detected at examination. The clinical examination of 24 additional relatives disclosed three further affected individuals, two men and one woman. In the four symptomatic patients the initial manifestations were walking abnormalities and leg stiffness with a mean age at onset (SD) of 46.75 (5.44) years (range 39-51). The mean disease duration was 13.2 (13.4) years (range 6-35), and it correlated well with clinical severity (SPRS score) $(r=0.975, p=$ 0.005). One patient was confined to bed and displayed knee and ankle contractures, another case needed a cane to walk, and two individuals were able to walk without aids. Interestingly, a patient had also had a miscarriage during her first pregnancy.

Gene testing revealed an heterozygous deletion spanning from the $5^{\prime}$-UTR to intron 4 of SPAST in the affected individuals and in one clinically unaffected woman. In three affected patients, the deletion also determined low mRNA levels of SPAST and DPY30, a component of the Set1-like multiprotein histone methyltransferase complex located upstream, head-to-head with SPAST.

Conclusion: Together with data described in a Japanese family, our findings seem to suggest that genes close to spastin might be candidates in modulating the clinical phenotype. This report endorses future research on the role of neighboring genes as potential players in SPG4 disease variability.

Keywords: SPG4, DPY30, Genetic modifier, Deletion

\section{Background}

Heterogeneity is a key feature of the hereditary spastic paraplegias (HSPs). To date, autosomal, sex-linked, and cytoplasmic inheritance have been reported, an ample array of complicated phenotypes disclosed, more than 70 loci mapped, and roughly 50 disease genes cloned [1,2]. In common clinical practice, the gene-after-gene testing strategy allows definition of the molecular basis in about half of HSP cases, unless peculiar features emerge during examination or follow-up.

* Correspondence: filippo3364@gmail.com

${ }^{3}$ IRCCS Stella Maris, via dei Giacinti 2, 56028 Pisa, Italy

Full list of author information is available at the end of the article
Mutations in SPAST/SPG4 encoding spastin represent the most common cause of autosomal dominant hereditary spastic paraplegias (AD-HSP) and also account for about $15 \%$ of sporadic cases [3,4]. In north-west Sardinia the relative frequency of HSP is higher than what is calculated in other Western European populations with an estimated crude prevalence of about 17.5/100,000 for AD-HSP [5]. As documented in several families and different populations $[4,6]$, the SPG4 phenotype is usually pure and inter- and intra-familial variability of the clinical presentation are well established [7]. In some cases, single nucleotide polymorphisms in SPAST and variants 
in additional genes are invoked as modifiers of age at onset, disease course and severity $[8,9]$.

We identified a novel SPAST mutation segregating in a Sardinian kindred (family IK).

\section{Case presentation}

The proband, a 54-year-old woman (IV-13) (Figure 1), manifested leg stiffness at age 39 and required a cane to walk at age 50. Neurological examination disclosed mild spasticity and weakness in the legs, enhanced deep tendon reflexes in all limbs, and bilateral Babinski sign. Case IV-13 also complained of urinary urgency, but no additional neurological symptoms or signs were detected at examination. The patient reported that her deceased father (III-03) and two uncles (III-02, III-04) had manifested similar gait abnormalities in adult age, although with different degree. Detailed clinical information and examinations were gathered from her living relatives.

\section{Materials and methods}

Total genomic DNA was purified by peripheral blood with standard methodologies. Analysis of common AD genes associated with HSP used traditional Sanger sequencing and the BigDye 3.1 Chemistry, as reported [5]. Search for copy number variation and gene deletion/duplication adopted reported array-comparative genomic hybridization $(\mathrm{aCGH})$ and multiple ligation-dependent probe amplication (MLPA) methodologies [10].

Twenty-four additional relatives were examined and sampled with written informed consent in family IK. Using oligonucleotide primers $\left(5^{\prime}-3^{\prime}\right)$ SPASTPrimer F, SPASTPrimer R1 and SPASTPrimer R2 that were designed flanking the mutation deletion breakpoints (sequences available upon request), we PCR-amplified genomic DNA to generate a single 955-bp fragment in wild-type individuals. The presence of the heterozygous SPAST deletion produced an additional fragment of 303bp (Figure 2).

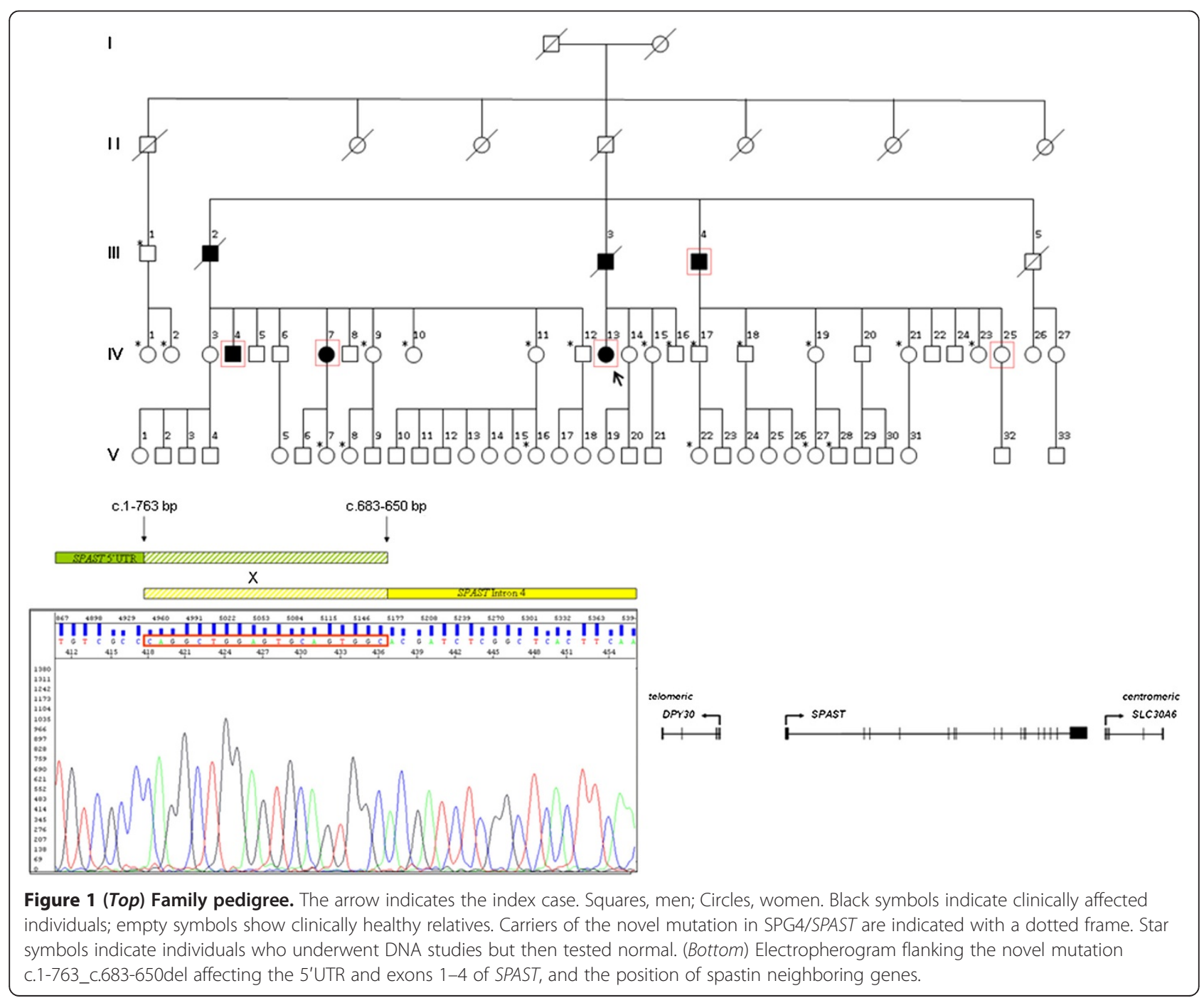



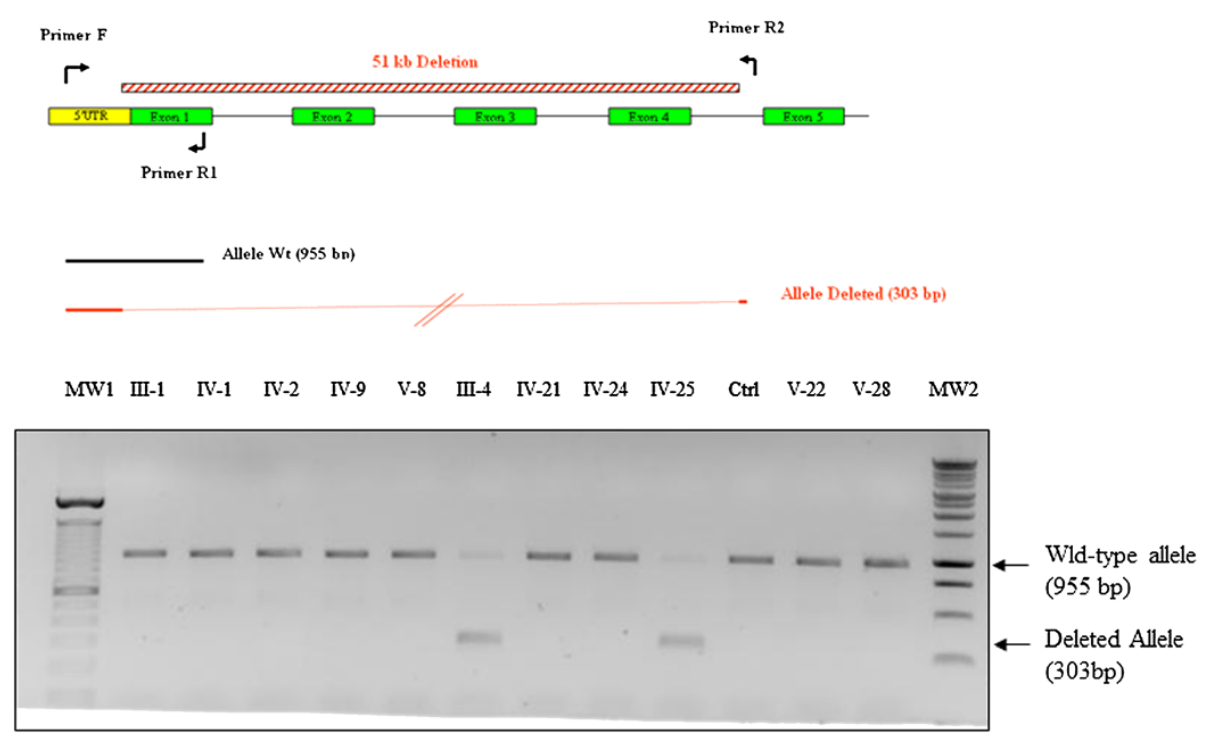

Figure 2 Rapid diagnostic genotyping of the multi-exon deletion detected in the IK family by a duplex-PCR method.

To test the effects on mRNA expression of the mutation deletion in SPAST, total blood RNA was extracted using a micro-scale total RNA separator kit (Ambion INC., Austin, TX). For standard gene expression experiments, the mRNA transcript levels were determined by qPCR runs in an ABI7500Fast system (Applied Biosystems, Foster City, CA) using the TaqMan Universal PCR Protocol, and human SPAST (Hs00368084_m1, Applied Biosystems), SLC30A6 (Hs01071782_m1), and DPY30 (Hs00261491_m1) as probes. GAPDH (Hs99999905_m1, Applied Biosystems) was used for endogenous normalization, and expressions were determined using the comparative $\mathrm{Ct}$ method [11]. Values were normalized in reference to the average control value obtained from three agematched normal control subjects. Statistical analyses used unpaired two-tailed Student-test (significance was set at $\mathrm{p}<0.05)$.

\section{Results}

No point mutations were found in SPAST and analyses of other frequent AD-HSP etiologies (namely, SPG3A/ ATL1, SPG31/REEP1, SPG10/KIF5A, SPG8/KIAA0196) were all normal in the proband. Combination of customized aCGH, MLPA analysis, and direct sequencing identified a novel heterozygous mutation (c.1-763_c.683-650del) spanning $51 \mathrm{~kb}$, from the $5^{\prime}$-UTR (and upstream regulatory elements) to intron 4 of SPAST. The deletion mutation was not found in the NCBI genomic structural variations database (http://www.ncbi.nlm.nih.gov/dbvar/?term=human + SPAST) nor in polymorphic databases.

Using a rapid PCR-based method to quickly genotype individuals in the family, and rule out the mutation in 500 ethnically-matched control chromosomes, we identified the new mutation in a total of five individuals, including the yet asymptomatic IV-25 (Figure 1). In all, global disease severity was assessed using the Spastic Paraplegia Rating Scale (SPRS) [12]. Table 1 summarizes clinical data in carriers of the novel SPAST mutation deletion. In the four symptomatic patients the initial manifestations were walking abnormalities and leg stiffness with a mean age at onset (SD) of 46.75 (5.44) years (range 39-51). The mean disease duration was 13.2 (13.4) years (range 6-35). Pearson's correlation coefficient indicated a positive correlation between disease duration and clinical severity (SPRS score) $(r=0.975, p=0.005)$. One patient (III-04) was confined to bed and displayed knee and ankle contractures, another needed a cane to walk, and two individuals were able to walk without aids. Interestingly, subject IV-07 had also had a miscarriage during her first pregnancy. At this point, we cannot state if IV-25 will develop any clinical manifestation in the near future or if she is a true not penetrant carrier of the mutation, since her present age is slightly younger than the mean age of onset of motor disturbances in the family. Reduced or no penetrance has repeatedly been described in spastin-related HSP kindred [1,3], including cases from Sardinia [10].

In three affected patients, we observed that the deletion also determined low mRNA levels of SPAST and DPY30, a component of the Set1-like multiprotein histone methyltransferase complex located upstream, headto-head with SPAST [15] (Figure 3).

\section{Discussion}

This report is the third description of a deletion characterizing the $5^{\prime}$-UTR of SPAST. Interestingly, the mutation also affected even more upstream sequences likely 
Table 1 Clinical features in the five patients harboring the mutation in the IK family

\begin{tabular}{|c|c|c|c|c|c|}
\hline & III-04 & IV-04 & IV-07 & IV-13 & IV-25 \\
\hline Age/Sex & $86 / \mathrm{M}$ & $53 / M$ & $60 / F$ & $54 / F$ & $42 / F$ \\
\hline Age at Onset, yrs & 51 & 47 & 50 & 39 & NA \\
\hline Disease duration, yrs & 35 & 6 & 10 & 15 & 0 \\
\hline SPRS score ${ }^{a}$ & 47 & 12 & 6 & 16 & 0 \\
\hline SPRS item $13^{b}$ & 4 & 1 & 1 & 1 & 0 \\
\hline Spasticity score $\mathrm{LL}^{\mathrm{C}}$ & 4 & 2 & 1 & 2 & 0 \\
\hline Muscle strenght score $L^{d}{ }^{d}$ & 0 & 5 & 4 & 4 & 5 \\
\hline Hyperreflexia UL/LL & Contracture & $0 /+++$ & $0 /++$ & $+/+++$ & $0 / 0$ \\
\hline Babinski sign & + & + & Indifferent & + & Indifferent \\
\hline Decreased vibration sense & na & No & No & No & No \\
\hline EMG/NCS & $\mathrm{na} / \mathrm{na}$ & Abnormal*/n & $n / n$ & $n / n$ & na/na \\
\hline Miscarriage/Pregnancy & & & $1 / 3$ & $0 / 0$ & $0 / 1$ \\
\hline
\end{tabular}

$\bar{M}$ man, F woman, UL Upper Limbs, LL Lower Limbs, na not available, EMG electromyography, NCS nerve conduction studies, $n$ Normal; *slight impairment but no frank signs of denervation.

${ }^{a}$ The SPRS score ranges from 0 (normal) to 52 (severely affected) [12]; ${ }^{b} 1=$ Urinary urgency (difficulties to reach toilet in time); $4=$ Permanent catheterization; ${ }^{\mathrm{c}}$ The Modified Ashworth Scale of Muscle Spasticity score ranges from 0 (no increase in tone) to 4 (affected parts rigid in flexion or extension) [13]; ${ }^{\mathrm{d}}$ The Medical Research Council Scale for Muscle Strength score ranges from 0 (no contraction) to 5 (normal strength) [14].

regulating SPAST and the neighbor DPY30 gene. Previously, a deletion was found in a Japanese family with clinical features and disease duration highly similar to our cases [16]. Also, six men and four women in a further Japanese kindred harbored a $70 \mathrm{~kb}$ deletion involving exons 1 to 4 of SPAST and also exons 1 to 3 of DPY30 [17]. Those patients had on average a teenage onset and a slowly progressive course leading to wheelchair in four, and use of a walking stick in one case. Other clinical features in that family were mild cognitive impairment and slight peripheral neuropathy. We believe that the presence of the spastin deletion might well explain a tendency towards less severe walking disability in family IK and in the Japanese kindred as described before in other families $[3,9]$. It is, however, intriguing that all affected Japanese women experienced miscarriages of unknown etiology similar to subject IV-07 in our kindred. Whether the shared feature of birth interruption relates to a similar defect in DPY3O is still questionable.
$D P Y 30$ is yet to be fully characterized but it seems to be essential for neural fate of embryonic cells, cellcycling and cellular proliferation $[15,18]$. In nematodes, null mutations in dpy-30 cause XX-specific lethality and the gene is required for normal development of $\mathrm{XO}$ males [19]. As it orthologue, it can be speculated that human DPY30 is also implicated in brain development and infertility [20] and when mutated might lead to miscarriages. The hypothetical function of the gene, however, cannot clearly explain how a low DPY30/mRNA expression (probably because of a position effect involving long-range gene regulatory elements) in the IK family with a milder phenotype agrees with the reduced mRNA levels (because of partial gene deletion) in the Japanese family with an earlier onset and apparently more severe neurological features [17]. We have no clear-cut explanation for this apparent "clinical riddle" other than raising the possibility of additional modifiers in the two families, maybe related to the different ethnic

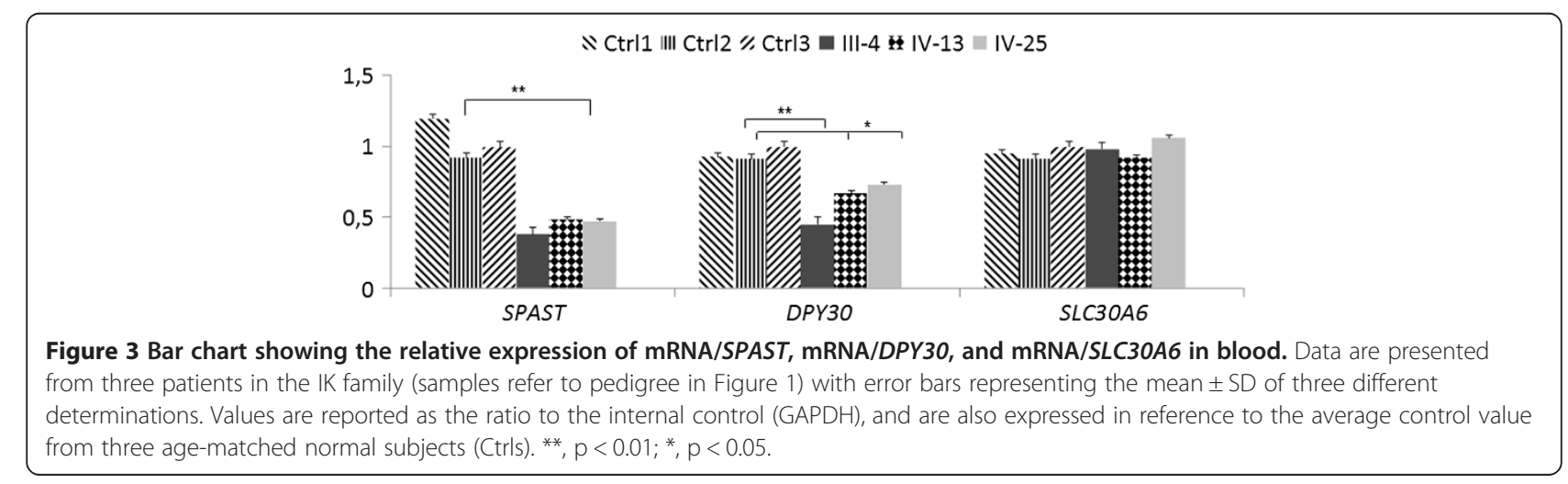


origin. Yet, alike the recent identification of a small deletion of SLC3OA6 - the gene flanking SPAST 3'UTR in another Italian SPG4 family [10], this report endorses future research on the role of neighboring genes as potential players in SPG4 disease variability.

\section{Conclusion}

We describe an AD-HSP Sardinian family where 5 out of several living members harbored a novel deletion affecting also the 5'UTR of SPAST and resulting in reduced expression of DPY30, the gene upstream SPAST in a head-to-head manner. If the presence of the spastin deletion might well explain a tendency towards less severe walking disability in our family, it is intriguing that a patient in our kindred experienced a miscarriage of unknown etiology similar to all affected women in a Japanese family harboring a SPAST and DPY3O deletion. This report encourages future research on the role of neighboring genes as potential players in SPG4 disease variability.

\section{Consent}

Written informed consent was obtained from the patients in the family for publication of this Case report.

\section{Competing interest}

The authors declare that they have no competing interests.

\section{Authors' contributions}

LR was involved in the acquisition and analysis of clinical data. AT and ES carried out the molecular genetic studies and participated in drafting the manuscript. MP was involved in the collection of patients and in the acquisition and analysis of clinical data. VA participated in the coordination of the study and revised the draft critically. FMS and LR conceived the study, participated in its design and coordination and contributed to draft the manuscript. All authors read and approved the final manuscript.

\section{Acknowledgements}

The authors thank the family members who participated in this study and Dr. Catherine J. Wrenn for expert editorial assistance. This work was partially supported by a grant from Telethon Italy (GPP10121A to FMS).

\section{Author details}

'Department of Clinical and Experimental Medicine, University of Sassari, Sassari, Italy. ${ }^{2}$ Department of Biomedical Sciences, University of Sassari, Sassari, Italy. ${ }^{3}$ IRCCS Stella Maris, via dei Giacinti 2, 56028 Pisa, Italy.

Received: 15 January 2014 Accepted: 12 March 2014

Published: 1 April 2014

\section{References}

1. Finsterer J, Löscher W, Quasthoff S, Wanschitz J, Auer-Grumbach M, Stevanin G: Hereditary spastic paraplegias with autosomal dominant, recessive, X-linked, or maternal trait of inheritance. J Neurol Sci 2012, 318:1-18.

2. Novarino G, Fenstermaker AG, Zaki MS, Hofree M, Silhavy JL, Heiberg AD, Abdellateef M, Rosti B, Scott E, Mansour L, Masri A, Kayserili H, Al-Aama JY, Abdel-Salam GM, Karminejad A, Kara M, Kara B, Bozorgmehri B, Ben-Omran T, Mojahedi F, Mahmoud IG, Bouslam N, Bouhouche A, Benomar A, Hanein S, Raymond L, Forlani S, Mascaro M, Selim L, Shehata N, et al: Exome sequencing links corticospinal motor neuron disease to common neurodegenerative disorders. Science 2014, 343:506-511.

3. Depienne C, Tallaksen C, Lephay JY, Bricka B, Poea-Guyon S, Fontaine B, Labauge P, Brice A, Durr A: Spastin mutations are frequent in sporadic spastic paraparesis and their spectrum is different from the one observed in familial cases. J Med Genet 2006, 43:259-265.

4. Loureiro JL, Brandão E, Ruano L, Brandão AF, Lopes AM, Thieleke-Matos C, Miller-Fleming L, Cruz VT, Barbosa M, Silveira I, Stevanin G, Pinto-Basto J, Sequeiros J, Alonso I, Coutinho P: Hereditary ataxia and spastic paraplegia in Portugal: a population-based prevalence study. JAMA Neurol 2013, 22:1-10.

5. Racis L, Tessa A, Di Fabio R, Storti E, Agnetti V, Casali C, Santorelli FM, Pugliatti M: The high prevalence of hereditary spastic paraplegia in Sardinia, insular Italy. J Neurol 2014, 261:52-59.

6. Erichsen AK, Inderhaug E, Mattingsdal M, Eiklid K, Tallaksen CM: Seven novel mutations and four exon deletions in a collection of Norwegian patients with SPG4 hereditary spastic paraplegia. Eur J Neurol 2007, 14:809-814.

7. Santorelli FM, Patrono C, Fortini D, Tessa A, Comanducci G, Bertini E, Pierallini A, Amabile GA, Casali C: Intrafamilial variability in hereditary spastic paraplegia associated with an SPG4 gene mutation. Neurology 2000, 55:702-705.

8. Hewamadduma CA, Kirby J, Kershaw C, Martindale J, Dalton A, McDermott CJ, Shaw PJ: HSP60 is a rare case of Hereditary Spastic Paraparesis, but may act as a genetic modifier. Neurology 2008, 70:1717-1718.

9. Svenson IK, Kloos MT, Gaskell PC, Nance MA, Garbern JY, Hisanaga S, Pericak-Vance MA, Ashley-Koch AE, Marchuk DA: Intragenic modifiers of hereditary spastic paraplegia due to spastin gene mutations. Neurogenetics 2004, 5:157-164.

10. Racis L, Di Fabio R, Tessa A, Guillot F, Storti E, Piccolo F, Nesti C, Tedde A, Pierelli F, Agnetti V, Santorelli FM, Casali C: Large deletion mutation of SPAST in a multi-generation family from Sardinia. Eur J Neurol 2013. Epub ahead of print.

11. Livak KJ, Schmittgen TD: Analysis of relative gene expression data using real-time quantitative PCR and the 2(-Delta Delta $C(T)$ ) method. Methods 2001, 25:402-408.

12. Schüle R, Holland-Letz T, Klimpe S, Kassubek J, Klopstock T, Mall V, Otto S, Winner B, Schöls L: The Spastic Paraplegia Rating Scale (SPRS): a reliable and valid measure of disease severity. Neurology 2006, 67:430-434.

13. Bohannon RW, Smith MB: Interrater reliability of a modified Ashworth scale of muscle spasticity. Phys Ther 1987, 67:206-207.

14. Compston A: Aids to the investigation of peripheral nerve injuries. Medical Research Council: Nerve Injuries Research Committee. His Majesty's Stationery Office: 1942; pp. 48 (iii) and 74 figures and 7 diagrams; with aids to the examination of the peripheral nervous system. By Michael O'Brien for the Guarantors of Brain. Saunders Elsevier: 2010; pp. [8] 64 and 94 Figures. Brain 2010, 133(10):2838-2844. PMID: 20928945.

15. Simboeck E, Gutierrez A, Cozzuto L, Beringer M, Caizzi L, Keyes WM, Di Croce L: DPY30 regulates pathways in cellular senescence through ID protein expression. EMBO J 2013. doi:10.1038/emboj.2013.159.

16. Iwanaga H, Tsujino A, Shirabe S, Eguchi H, Fukushima N, Niikawa N, Yoshiura K, Equchi K: Large deletion involving the $5^{\prime}$-UTR in the spastin gene caused a mild phenotype of autosomal dominant hereditary spastic paraplegia. Am J Med Genet 2005, 133:13-17.

17. Miura S, Shibata H, Kida H, Noda K, Toyama T, Iwasaki N, Iwaki A, Ayabe M, Aizawa H, Taniwaki T, Fukumaki Y: Partial SPAST and DPY30 deletions in a Japanese spastic paraplegia type 4 family. Neurogenetics 2011, 12:25-31.

18. Cho YW, Hong T, Hong S, Guo H, Yu H, Kim D, Guszczynski T, Dressler GR, Copeland TD, Kalkum M, Ge K: PTIP associates with MLL3- and MLL4containing histone $\mathrm{H} 3$ lysine 4 methyltransferase complex. J Biol Chem 2007, 282:20395-20406.

19. Hsu DR, Meyer BJ: The dpy-30 gene encodes an essential component of the Caenorhabditis elegans dosage compensation machinery. Genetics 1994, 137:999-1018.

20. Hsu DR, Chuang PT, Meyer BJ: DPY-30, a nuclear protein essential early in embryogenesis for Caenorhabditis elegans dosage compensation. Development 1995, 121:3323-3334.

doi:10.1186/1471-2350-15-39

Cite this article as: Racis et al:: Novel SPAST deletion and reduced DPY30 expression in a Spastic Paraplegia type 4 kindred. BMC Medical Genetics 2014 15:39. 